\title{
Preface, Conventions, Acknowledgments
}

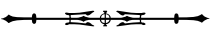

\section{pURPOSE}

A number of authors have addressed the architecture and sculpture of colonial Mexico. There is George Kubler and Martin Soria, Art and Architecture in Spain and Portugal and Their American Dominions; George Kubler, Mexican Architecture of the Sixteenth Century; John McAndrew, The Open-Air Churches of Sixteenth-Century Mexico; Robert Mullen, Dominican Architecture in Sixteenth-Century Oaxaca; Manuel Toussaint, Colonial Art in Mexico. Monographs and regional studies also exist. None, however, serve the needs of the general reader or college student who seeks a comprehensive account of architecture and its attendant sculpture for the entire colonial period. It is my intention to satisfy that need with this book.

\section{ORGADIZATION}

I estimate nearly 100,000 churches and civic buildings were constructed in Mexico between I 530 and I 800 , the period of its colonial architecture. I see colonial Mexico as enveloped in two worlds, that of the city and that of the pueblo. Many structures are quite ordinary. Others reflect the pageantry of imperial urban display, works of ac- 
complished architects. A surprising number of churches are distinctive, even unique. In this work I shall concentrate in chapters 2 through 6 on those features distinguishing the architecture and sculpture of each world, organized into three time frames-the formative era, from the I 540 os into the I600s; a transitional phase, from I 650 to I 750 ; and the age of fulfillment, from I 750 to I 800 . Chapter 7 is devoted to the seventeenth- and eighteenth-century mission churches in Spain's northern frontier, our Southwest.

\section{ACKDOC(LEDGMETTS}

Most photographs and drawings are mine. The task of making the prints, however, was almost entirely accomplished by David Zook. He created hundreds, each made to maximize half-tone reproduction, each a work of art. He met the challenge of transforming color slides into black and white negatives and, eventually, prints. Some illustrations, of varying sizes and quality, were found in books. These he photographed with consummate skill, their prints matching others perfectly. I am truly indebted to David Zook for the professional capability and personal care he put into the task. When ill health made difficult the final task of having the negatives made into quality prints, David took on the role of film manager. In doing so he relieved me of a great burden. His performance was outstanding. Thanks, Dave.

I owe a debt of gratitude to Lic. Cecilia Gutiérrez Arriola, Director of the Photographic Archives of the Instituto de Investigaciones Estéticas, Universidad Nacional Autónoma de México, for providing a number of excellent photographs either of places I lacked or of higher quality. Also in Mexico I wish to thank Arq. Víctor Jiménez Muñoz, director of the publishing firm CODEX Editores, for his strong support. He performed the daunting task of checking the manuscript for accuracy and clarity; his suggestions were meticulously followed.

Among my colleagues I am indebted to Dr. Bernard L. Fontana and Dr. Norman Neuerburg. They were unstinting in their assistance concerning, respectively, the missions of Arizona and California. Another colleague, Mardith Shuetz-Miller, associated with the Arizona State Museum, played a key role in the final review, providing insights 
and offering many solid suggestions. In San Antonio, Dr. Rosalind Z. Rock, Park Historian, was instrumental in obtaining measured drawings of the San Antonio missions and other valuable data. I am indebted to Mónica Guajardo M. for creating the excellent pen and ink drawing that is now Fig. 3.I.

I doubt the manuscript would have been accepted without the critical and corrective eye of my editor, Dr. Janet F. Williams McDonald, a very busy medical person. I can never sufficiently express my appreciation nor conceal my wonder.

My patient and ever-understanding wife, Anne, provided constant encouragement and "protection" from romping grandchildren. To her, with all my love, I dedicate this book.

\section{CQORDS ATD MEASCREMENTS}

A number of Spanish words have no proper English equivalent. After their first italicized appearance they are used as normal English words. For example convento becomes convento. Meaning is made evident contextually. A glossary has been added for convenience. I have chosen not to hyphenate such words as "prehispanic" or "neoclassic."

"Mexico" can mean either the capital city or the nation. Where the context is not absolutely clear, the word will be identified as one or the other. Up to I 820 the term "The Viceregency of New Spain" (Nueva España) was used to identify today's Mexico (which at one time included areas in the United States from the Atlantic to the Pacific oceans.) As a nation, Mexico now has 3 I states plus the Federal District (essentially Mexico City). In the text states are shown in parentheses following the place name, e.g., Tlaxcala (Tlaxcala).

Measurements are metric. One meter equals 39.3 I inches.

\section{MAIP ADVISORY}

Many of the pueblos mentioned in the book are difficult to locate. The maps in this book were enlarged in order to more readily show the pueblos' relative location. For this purpose Mexico was divided 
into three zones-north, central, and south. In each of these zones only the states and places pertinent to the book are named, except that some key places have been added to assist in orientation. With a good road map of Mexico, such as that available through the American Automobile Association, the actual location of the pueblo or city can be pinpointed, and the roads and routes thereto can be determined. The scale of the normal road map for all of Mexico is not large enough to show all the places mentioned in Oaxaca. To locate those pueblos it will be necessary to purchase a road map of that state. Some of the cited places can be reached only by high-wheeled vehicle. 


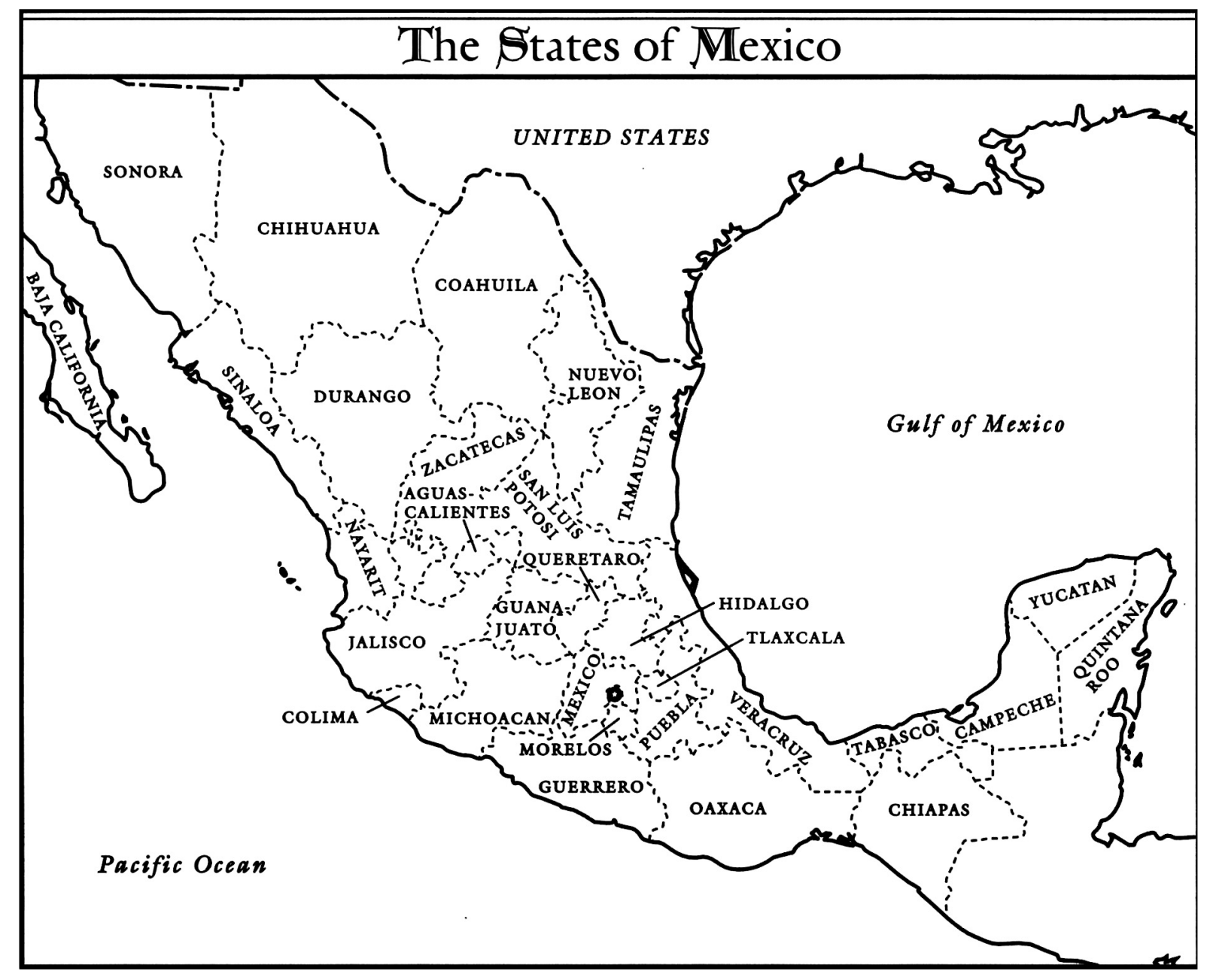




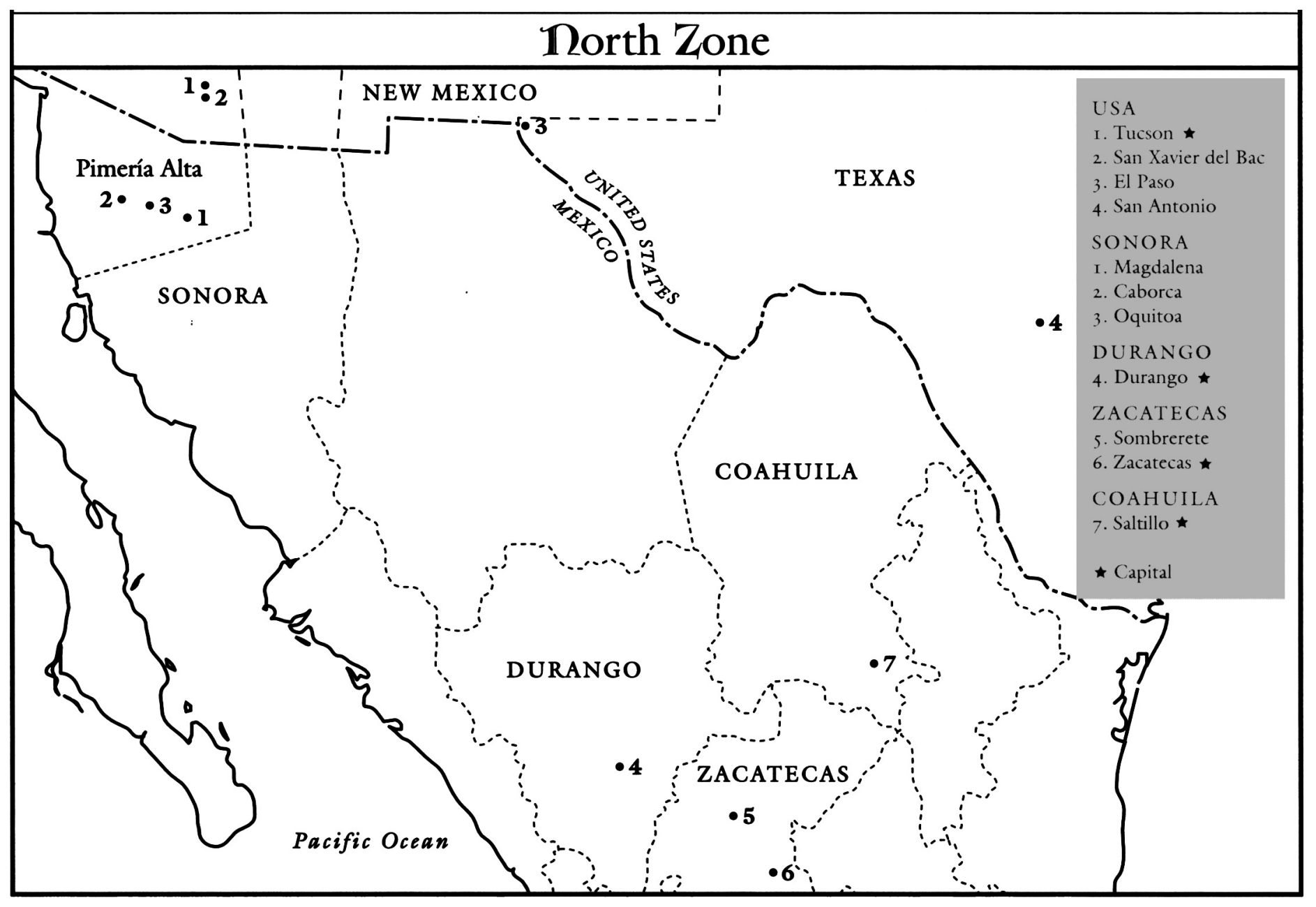




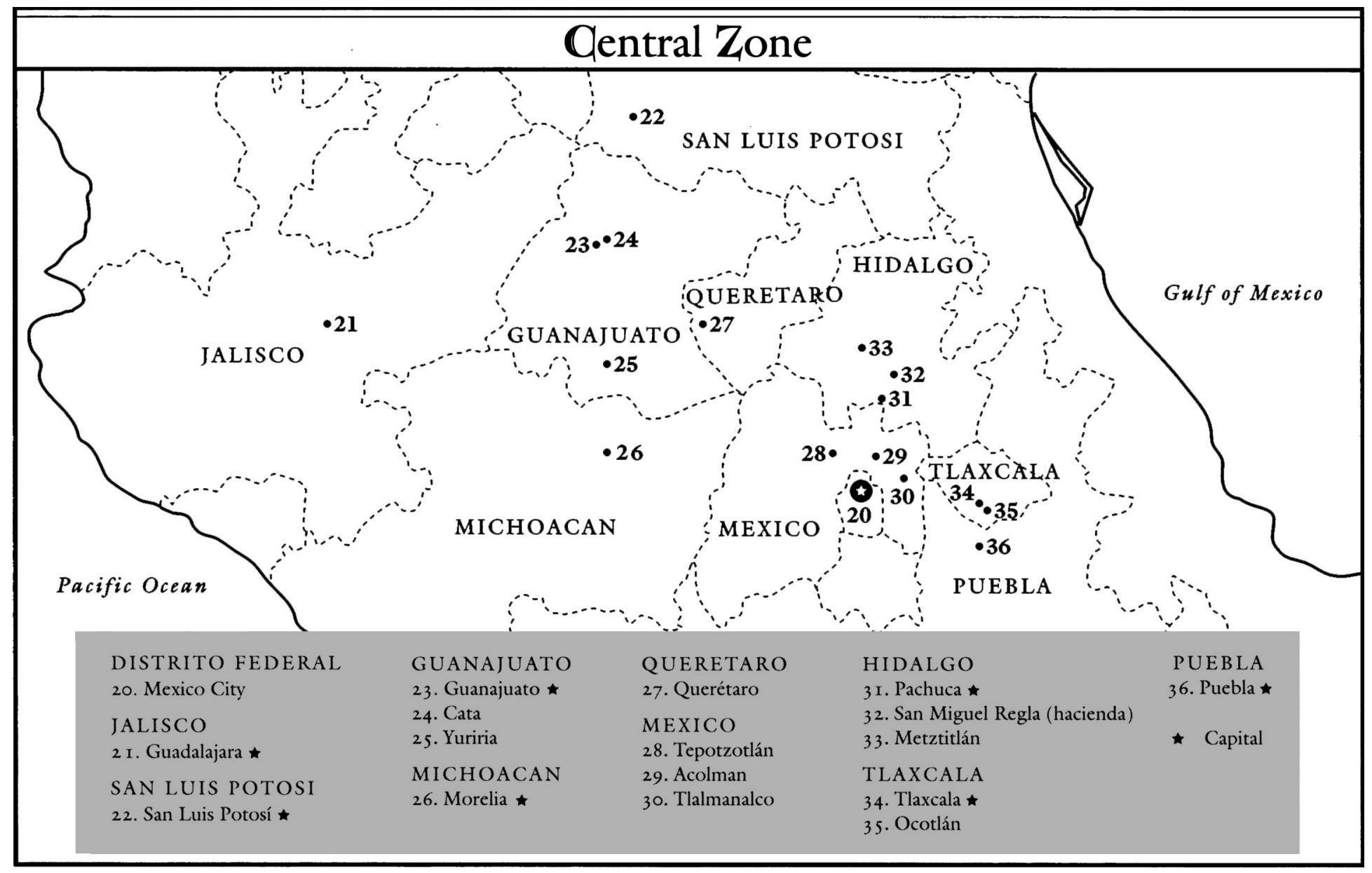




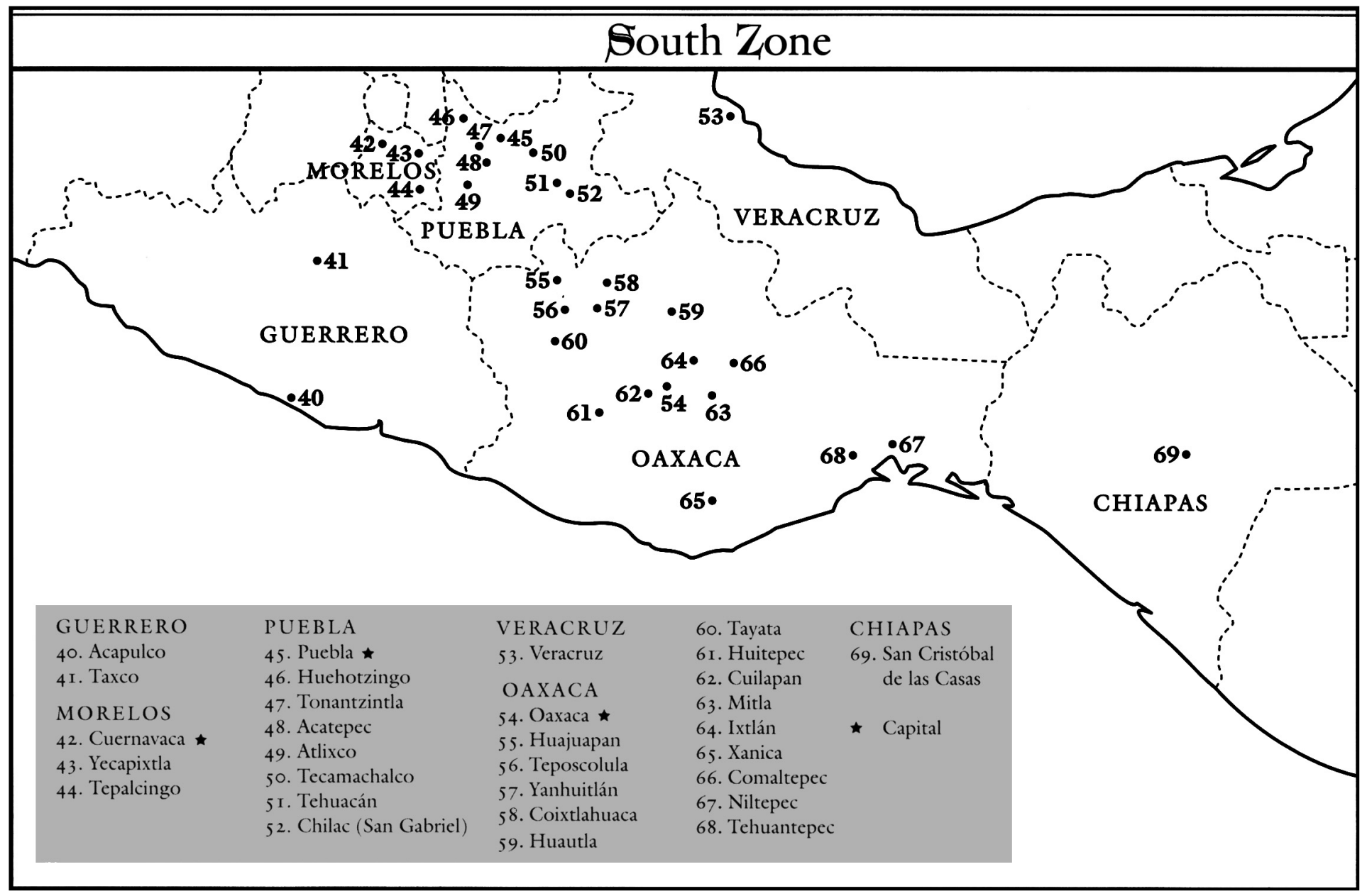




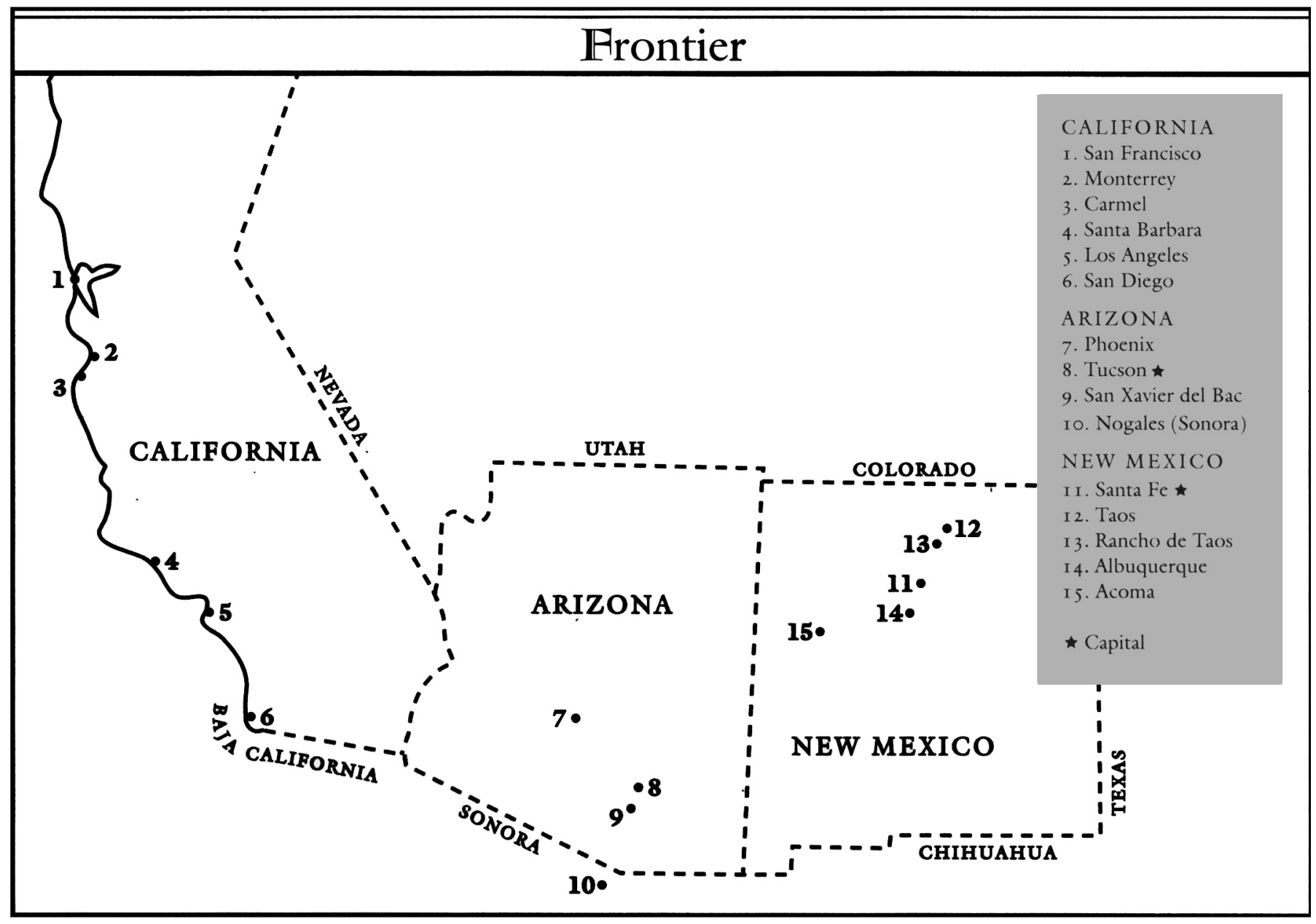


THIS PAGE INTENTIONALLY LEFT BLANK 